\title{
A 225 kW Direct Driven PM Generator Adapted to a Vertical Axis Wind Turbine
}

\author{
S. Eriksson, H. Bernhoff, and M. Leijon \\ Swedish Centre for Renewable Electric Energy Conversion, Division for Electricity, Department of Engineering Sciences, \\ Uppsala University, P.O. Box 534, 75121 Uppsala, Sweden
}

Correspondence should be addressed to S. Eriksson, sandra.eriksson@angstrom.uu.se

Received 14 March 2011; Revised 24 August 2011; Accepted 24 August 2011

Academic Editor: Jose Pomilio

Copyright ( $\odot 2011$ S. Eriksson et al. This is an open access article distributed under the Creative Commons Attribution License, which permits unrestricted use, distribution, and reproduction in any medium, provided the original work is properly cited.

A unique direct driven permanent magnet synchronous generator has been designed and constructed. Results from simulations as well as from the first experimental tests are presented. The generator has been specifically designed to be directly driven by a vertical axis wind turbine and has an unusually low reactance. Generators for wind turbines with full variable speed should maintain a high efficiency for the whole operational regime. Furthermore, for this application, requirements are placed on high generator torque capability for the whole operational regime. These issues are elaborated in the paper and studied through simulations. It is shown that the generator fulfils the expectations. An electrical control can effectively substitute a mechanical pitch control. Furthermore, results from measurements of magnetic flux density in the airgap and no load voltage coincide with simulations. The electromagnetic simulations of the generator are performed by using an electromagnetic model solved in a finite element environment.

\section{Introduction}

The use of wind power is increasing all over the world, and there are several different types of electrical systems available for converting the wind power to electricity, but no single technology is dominating the market [1]. In this paper a direct driven permanent magnet (PM) synchronous generator is presented [2-4]. The generator presented here has been specifically designed to be directly driven by a vertical axis wind turbine (VAWT) [5] and to be placed on ground level. One of the advantages of using a VAWT is that it is omnidirectional; that is, it can accept wind from any direction and does not need a yawing mechanism. The present vertical axis turbine is a straight-bladed Darrieus turbine [6]. A presentation of the design of the same type of wind turbine can be found in [7]. A more extensive presentation of the generator type, generator experiments, and verification of simulations can be found in $[8,9]$.

A direct driven generator is spared from losses, maintenance, and costs associated with a gearbox. However, direct drive yields a larger generator than with a generator connected through a gearbox. For a vertical axis wind turbine where the generator can be placed on ground level, the size and weight are of less concern. The generator can therefore be optimized considering efficiency and cost instead of focusing on lowering the weight. Thus, the vertical orientation of the axis allows for a general study of generator design freed from weight and size constrains.

The presented generator is unique in several ways. It is a permanent magnet generator with many poles and a large diameter. It is cable wound, which means that the stator has circular cables. It has a relatively high voltage. The generator is designed to have a low rotational speed, since it is directly coupled to a vertical axis wind turbine. The generator also has an unusually high overload capacity in order to enable electrical control and braking of the turbine. Furthermore, it has a low reactance, in order to fulfil the design requirements. The electromagnetic simulations of the generator are performed by using an electromagnetic model. The model is described by a combined field and circuit equation model and is solved in a finite element environment.

This paper presents the generator design objectives, results from generator simulations, and results from initial tests of the generator. Two important features of this type of 
generator is the high efficiency over the whole operational regime and the desired overload capability. Therefore, these aspects have been investigated more thoroughly in simulations by taking wind turbine aerodynamic behaviour into consideration. In addition, experiments have been performed to verify the simulations. Designing, building, and testing of the generator were done at Uppsala University during 2009. The generator was installed in a $200 \mathrm{~kW}$ VAWT in 2010, which has been built in Falkenberg, Sweden.

\section{Theory}

2.1. Electromagnetic Model. Electromagnetic simulations using the finite element method (FEM) are performed in order to simulate the generator's behaviour at different loading conditions. In the simulations the electromagnetic field inside the generator is assumed to be axisymmetrical and is therefore modelled in two dimensions. Three-dimensional effects such as end-region fields are taken into account by introducing coil end impedances in the circuit equations of the windings. The permanent magnets are modelled by surface current sources.

The electromagnetic model is described by a combined field and circuit equation model. The field equation (1) originates from Maxwell's equations,

$$
\sigma \frac{\partial A_{z}}{\partial t}-\nabla \cdot\left(\frac{1}{\mu} \nabla A_{z}\right)=-\sigma \frac{\partial V}{\partial z},
$$

and $\sigma$ is the conductivity, $\mu$ is the permeability, $A_{z}$ is the axial magnetic potential, and $\partial V / \partial z$ is the applied potential. The right-hand term of (1) corresponds to the current density constituted by the current density in the armature and a current density representing the permanent magnets. The magnetization curve of the stator steel is modelled as a nonlinear, single-valued curve, that is, $\mu$ in (1) is not constant for the stator steel, taking saturation into account. The circuit equations are described by

$$
\begin{gathered}
I_{a}+I_{b}+I_{c}=0 \\
U_{a b}=U_{a}+R_{s} I_{a}+L_{s}^{\text {end }} \frac{\partial I_{a}}{\partial t}-U_{b}-R_{s} I_{b}-L_{s}^{\text {end }} \frac{\partial I_{b}}{\partial t}, \\
U_{c b}=U_{c}+R_{s} I_{c}+L_{s}^{\text {end }} \frac{\partial I_{c}}{\partial t}-U_{b}-R_{s} I_{b}-L_{s}^{\text {end }} \frac{\partial I_{b}}{\partial t}
\end{gathered}
$$

where $I_{a}, I_{b}$, and $I_{c}$ are the conductor currents, $U_{a b}$ and $U_{c b}$ are the terminal line voltages, $U_{a}, U_{b}$, and $U_{c}$ are the terminal phase voltages obtained from solving the field equation, $R_{s}$ is the cable resistance, and $L_{s}^{\text {end }}$ represents the coil end inductance.

After a generator geometry is decided, the generator parts are assigned different material properties such as conductivity, permeability, density, and sheet thickness. The electromagnetic model is solved in the finite element environment ACE [10]. The mesh is finer close to critical parts such as the airgap and coarser in areas like the yoke of the stator. Since the generator is symmetric, only a few poles have to be modelled.
Simulations can be performed either in the stationary mode where the results are given for a fixed rotor position or in a dynamic mode including the time dependence and thereby giving more accurate results. The simulations have been verified by comparison with experimental results for a generator similar to the one studied here $[8,9]$.

2.2. Electromagnetic Losses and Efficiency. The electrical efficiency, $\eta$, of a generator is found from

$$
\eta=\frac{P_{\mathrm{el}}}{P_{\mathrm{el}}+P_{\text {losses }}},
$$

where $P_{\mathrm{el}}$ is the electrical output power and $P_{\text {losses }}$ are the total electromagnetic losses found from.

$$
P_{\text {losses }}=P_{\mathrm{Fe}}+P_{\mathrm{Cu}} \text {, }
$$

where $P_{\mathrm{Fe}}$ are the iron losses and $P_{\mathrm{Cu}}$ are the copper losses, see below. The iron losses per cubic meter stator steel can be found from the following equation $[11,12]$ :

$$
\begin{aligned}
P_{\mathrm{Fe}, \mathrm{vol}}= & k_{f} k_{\mathrm{hy}} B_{m}^{2} f+k_{f} k_{\mathrm{eddy}}\left(B_{m} f\right)^{2} \\
& +k_{f} k_{\mathrm{exc}}\left(B_{m} f\right)^{1.5}+P_{\text {rot,vol }}
\end{aligned}
$$

where $k_{f}$ is the stacking factor, $k_{\text {hy }}$ is the hysteresis losses coefficient, $k_{\text {eddy }}$ is the eddy current losses coefficient and $k_{\text {exc }}$ is the excess losses coefficient, $B_{m}$ is the peak magnetic flux density, $f$ is the frequency, and $P_{\text {rot,vol }}$ denotes the rotational losses [13]. The eddy current losses coefficient can be calculated according to

$$
k_{\text {eddy }}=\pi^{2} \frac{\sigma d^{2}}{6},
$$

where $\sigma$ is the conductivity and $d$ is the steel thickness, so the eddy current losses are dependent on the steel thickness squared and can be decreased by choosing thinner steel plates. The coefficients for hysteresis and excess losses $k_{\text {hy }}$ and $k_{\text {exc }}$ are found from the loss characteristics specified from the steel manufacturer [14].

The iron losses have to be multiplied with the total stator steel volume, $V_{s}$, and a loss correction factor to find the total losses:

$$
P_{\mathrm{Fe}}=1.5 \cdot P_{\mathrm{Fe}, \mathrm{vol}} V_{s} \text {. }
$$

In the simulations a loss correction factor of 1.5 is used for all iron losses. The loss correction factor represents differences in the theoretical modelling of iron losses and experimental measurements, caused for instance by stray losses, and the value of 1.5 is verified for a similar generator in [15].

The copper losses consist of resistive losses and a small amount of eddy current losses in the copper conductors and can be written as

$$
P_{\mathrm{Cu}}=3 R_{s} I^{2}+P_{\mathrm{Cu}}^{\mathrm{eddy}}
$$

where $R_{s}$ is the cable resistance, $I$ is the current, and $P_{\mathrm{Cu}}^{\text {eddy }}$ denotes the eddy current losses in the conductors. The eddy 
TABLE 1: Wind turbine characteristics.

\begin{tabular}{lc}
\hline Rated output power $(\mathrm{kW})$ & 200 \\
Rated rotational speed $(\mathrm{rpm})$ & 33 \\
Swept area $\left(\mathrm{m}^{2}\right)$ & 624 \\
Tower height $(\mathrm{m})$ & 40 \\
Number of blades & 3 \\
\hline
\end{tabular}

current losses in the cables are included in the simulations but only constitute a small amount of the total copper losses.

Eddy current losses in the PMs and in the iron ring that the PMs are mounted on are expected to be small as they are subjected to mostly DC magnetic field and are therefore neglected.

The mechanical losses in a direct driven electric machine, consisting of friction in couplings and bearings and windage losses, are usually small. Here, mechanical losses are not considered.

\section{Method}

3.1. Wind Turbine Characteristics. The generator was designed to be used together with a VAWT with characteristics presented in Table 1 . The vertical axis turbine is a threebladed turbine with a cross-sectional area of $624 \mathrm{~m}^{2}$. The VAWT does not have a pitch control. It is passively stall controlled by control of the rotational speed through the generator. Therefore, the generator needs to be robust and has a large maximum torque. The required overload capability was chosen from aerodynamic simulations in order to ensure stall control capability.

The variable speed turbine will be controlled according to the control strategy presented in Table 2 . At wind speeds between 4 and $6 \mathrm{~m} / \mathrm{s}$ the turbine will be run at a higher speed than optimum in order to limit the operational speed window from 18 to $33 \mathrm{rpm}$, that is, 0.55 to $1 \mathrm{p} . \mathrm{u}$. This is important for structural dynamic purposes. At wind speeds between 6 and $10.9 \mathrm{~m} / \mathrm{s}$, the wind turbine is controlled for optimum aerodynamic efficiency. The rotational speed is kept constant at $33 \mathrm{rpm}$ for wind speeds between 10.9 and $11.7 \mathrm{~m} / \mathrm{s}$. At wind speeds above $11.7 \mathrm{~m} / \mathrm{s}$, the rotational speed is controlled to stall the turbine. Thereby an even power production of $200 \mathrm{~kW}$ can be achieved from wind speeds of $11.7 \mathrm{~m} / \mathrm{s}$ up to the shut-down wind speed.

3.2. Generator Design Objectives. The most important generator design objectives were as follows:

(i) a design adapted to the turbine,

(ii) a design adapted for diode rectification,

(iii) low speed (i.e., direct drive),

(iv) high overload capacity,

(v) high efficiency,

(vi) high reliability and low need for maintenance,

(vii) low cost.
TABLE 2: Control strategy.

\begin{tabular}{lcc}
\hline Wind speed $(\mathrm{m} / \mathrm{s})$ & Rot. speed $(\mathrm{rpm})$ & Control rule \\
\hline $0-4$ & 0 & Not operated \\
$4-6.0$ & 18 & Speed regulation \\
$6.0-10.9$ & $18-33$ & Optimum eff. reg. \\
$10.9-11.7$ & 33 & Stall regulation \\
$11.7-25$ & $28-33$ & Constant power reg. \\
$>25$ & 0 & Shut down \\
\hline
\end{tabular}

The directly driven turbine operates at variable speeds. Therefore, the generator should be designed to have a high efficiency for all operational speeds and loads. In a study, the average losses for several variable speed generators, similar to this generator, were compared [16]. The result showed that the generator with highest average efficiency also had a rather high overload capability, low load angle, and low reactance.

A generator designed with a low load angle can handle a higher power than it is rated for. Thus, low load angle enables electrical braking of the turbine and also the possibility to extract more energy in high wind speeds. The turbine's power absorption can thereby be controlled electrically. This electrical power control can replace an active mechanical power control of the wind turbine, such as pitch control. Furthermore, the electrical control responds much faster than the mechanical control and is not subject to mechanical wear.

A variable speed generator needs a frequency converter before it is connected to the grid, allowing the voltage and current levels to be chosen freely. The converter consists of a rectifier and an inverter. For this concept, diodes will be used for rectification, which is a cheap and reliable option with low losses. When using diodes instead of an active rectifier no reactive power can flow to or from the generator. Therefore, the generator needs to have a low load angle throughout the operational regime.

The generator is designed with a low reactance which gives a machine that fulfils several of the requirements:

(i) low reactance implies a low load angle, which enables the use of diodes for rectification,

(ii) high efficiency [16],

(iii) high overload capability, which enables electrical control,

(iv) low voltage drop even at high loads.

3.3. Simulations. The electromagnetic simulations of the generator using the finite element method (FEM) are performed by using the model described in Section 2.1. Stationary simulations are performed to dimension the generator in order to save time during the iterative design process. Dynamic simulations are then performed to verify the chosen design and to simulate the generator in different modes of operation. All presented results are from dynamic simulations. The generator model is connected to a resistive load, which gives a good estimate for modelling the braking torque since the generator is connected to the dump load before the rectifier by a circuit breaker. For modelling the efficiency 
and armature reaction, this is a simplification but will give rather accurate results. However, the copper losses could be expected to be slightly higher during diode rectification due to current peaks. The efficiency is modelled according to the theory described in Section 2.2. The generator has been simulated with a varying rotational speed and a varying load sweeping through a wide range of values to cover the whole operational interval as well as extreme cases of braking at higher rotational speeds than expected during normal operation.

The electrical efficiency at different wind speeds has been calculated by using the values found from FEM simulations of the generator for varying load and speed and combining these with the control strategy presented in Table 2. A theoretical curve of the aerodynamic efficiency and its dependency on wind speed and rotational speed is used in the simulations. The aerodynamic efficiency is calculated using complex aerodynamic models for vertical axis wind turbines [17]. An average value of the losses in the generator is calculated using the results from the calculations of the electrical efficiency at different wind speeds and assuming a Rayleigh distributed wind speed with an average wind speed of $6.7 \mathrm{~m} / \mathrm{s}$.

The turbine torque is derived from theoretical calculations based on complex aerodynamic models [17]. The unlikely load case called "extreme coherent gust with direction change" in IEC standard 61400-1, where the wind speed increases by $15 \mathrm{~m} / \mathrm{s}$ in 10 seconds, is considered [18]. This is an extreme operational case which is unlikely to occur.

3.4. Experiments. Experiments were performed after the generator was constructed. A Gauss/Teslameter (Sypris Model 7010) was used to measure the magnetic flux density in the airgap at high accuracy. The generator was accelerated, and several measurements of the voltage were done at a rotational speed of $18.5 \mathrm{rpm}$. An oscilloscope (Tektronix TDS2014) and high voltage probes (Tektronix P5120) were used to measure the voltage.

\section{Results and Discussion}

4.1. Generator Characteristics. The generator characteristics were derived by dynamic simulations using the electromagnetic model described in Section 2.1. The mechanical design of the generator, developed in SolidWorks, has been focused on finding a stiff design which can maintain the airgap and withstand large airgap forces during faulty conditions.

The stator winding consists of PVC insulated circular cables. The circular shape gives an evenly distributed electric field in the cables and hence makes better use of the insulation material [19]. In large machines, a cable wound generator is of great interest since it enables the use of higher operating voltage than for traditionally wound machines [19]. A generator with high rated voltage and consequently a low rated load angle has a high maximum torque [20].

The low reactance is achieved by choosing a relatively high voltage for the given power rating, that is, a low rated load angle. The generator has 36 poles, and the armature
TABLE 3: Generator characteristics at rated conditions.

\begin{tabular}{lc}
\hline Active power $(\mathrm{kW})$ & 225 \\
No load L-L voltage (V) rms & 839 \\
Load L-L voltage (V) rms & 810 \\
Current (A) rms & 160 \\
Electrical efficiency (\%) & 96.7 \\
Speed (rpm) & 33 \\
Torque (kNm) & 65 \\
$X / R$-ratio (p.u.) & 0.17 \\
Load angle $\left(^{\circ}\right)$ & 9.9 \\
\hline
\end{tabular}

is wound as a wave winding with $5 / 2$ slots per pole and phase and six cables per slot. The winding is divided into two parallel current paths.

The rotor of the generator is equipped with large, surface-mounted, arched, high-energy magnets made of Neodymium Iron Boron. The stator consists of steel laminations with a thickness chosen as a compromise between losses in the stator steel and cost. The generator is rated at $225 \mathrm{~kW}$ as the wind turbine system is designed to deliver $200 \mathrm{~kW}$ to the grid at rated speed. The higher rating of the generator accommodates for some losses in the electrical system as well as possible deviations between the simulation programs (aerodynamic and electrical) and reality. The generator power rating is given in $\mathrm{kW}$ rather than the more conventional $\mathrm{kVA}$, since the generator will be rectified through diodes. The generator characteristics are presented in Table 3, where L-L voltage means line-to-line voltage. The voltage drop is only $3.3 \%$ at rated conditions. The ratio between the machine reactance, $X$, and the rated load, $R$, the $X / R$-ratio, is 0.17 p.u., where typical generator values for the $X / R$-ratio are in the range of 1.7 to 3.3 p.u. [21]. The load angle is less than 10 degrees at rated operation.

The maximum torque of the generator is $218 \mathrm{kNm}$, which is 3.3 times the rated torque. The generator overload capability is used in two different ways when the wind turbine is operated. First, it is used to control the DC level voltage at high power. Second, the generator can be connected to a dump load that will brake the turbine in a few seconds from any operating regime. Thereby an electrical control is established and the overload capability makes the operation at rated power level safe and reliable.

During manufacturing a few deviations occurred from the original design. All the simulations presented here are based on the actual generator geometry as opposed to the theoretical design. A picture of the generator and the magnetic flux density in the designed generator from dynamic simulations is shown in Figure 1.

\subsection{Results from Simulations}

4.2.1. Efficiency. The generator has been simulated for all different rotational speeds and power levels appropriate to find the efficiency over the whole operational regime when the turbine is operated according to the chosen control strategy; see Table 2. The result can be seen in Figure 2. 

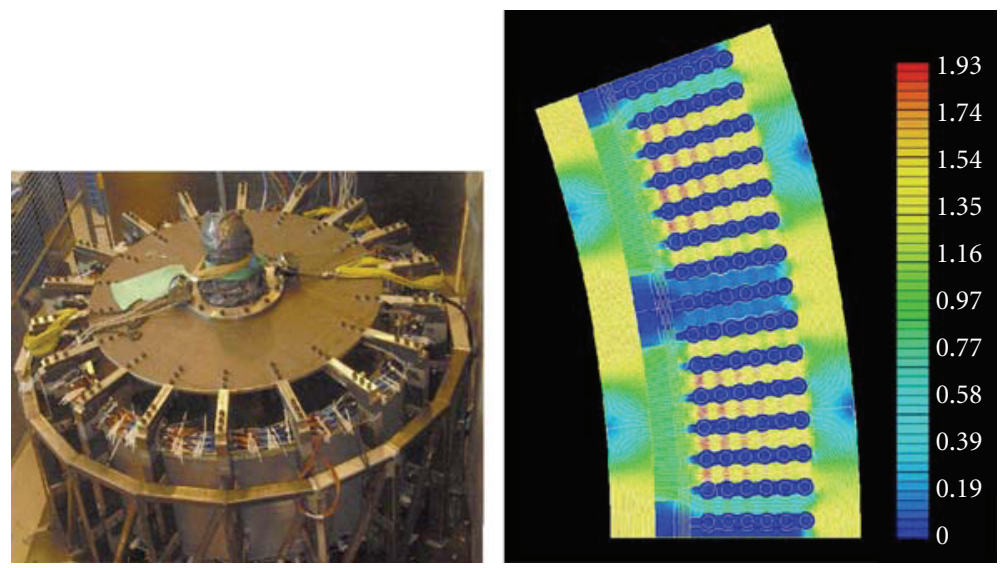

FIGURE 1: The constructed generator during experiments to the left and the magnetic flux density $(T)$ in the generator to the right.

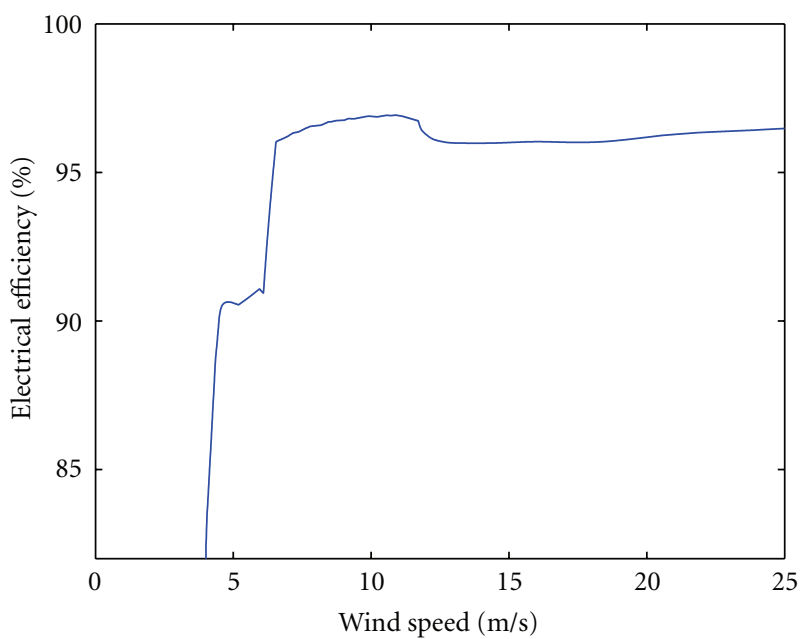

Figure 2: Electrical efficiency of the generator at different wind speeds.

The strange shape of the curve is a result from the different control strategies. At wind speeds above $11.7 \mathrm{~m} / \mathrm{s}$ the rotational speed needs to be decreased in order to limit the power absorption to $225 \mathrm{~kW}$ by stall regulation. The voltage will then decrease and the current will increase, resulting in increasing copper losses and lower efficiency. The efficiency is shown to be high, above $96 \%$ for all wind speeds above $6.6 \mathrm{~m} / \mathrm{s}$. The generator efficiency is kept high even when the turbine is operating in the aerodynamic stall regime. For wind speeds above $11.7 \mathrm{~m} / \mathrm{s}$, the amount of losses remains roughly constant. The average efficiency during operation becomes $96.0 \%$, which is close to the rated value of $96.7 \%$.

4.2.2. Brake Capacity. The dump load, rated at $1.1 \Omega$, is designed to brake the turbine efficiently over the entire operational regime. A figure of the braking torque from the generator when connected to the dump load at different rotational speeds can be seen in Figure 3 together with the turbine torque. The dump load can brake the turbine for all extreme loads at rotational speeds up to $37.1 \mathrm{rpm}$. However,

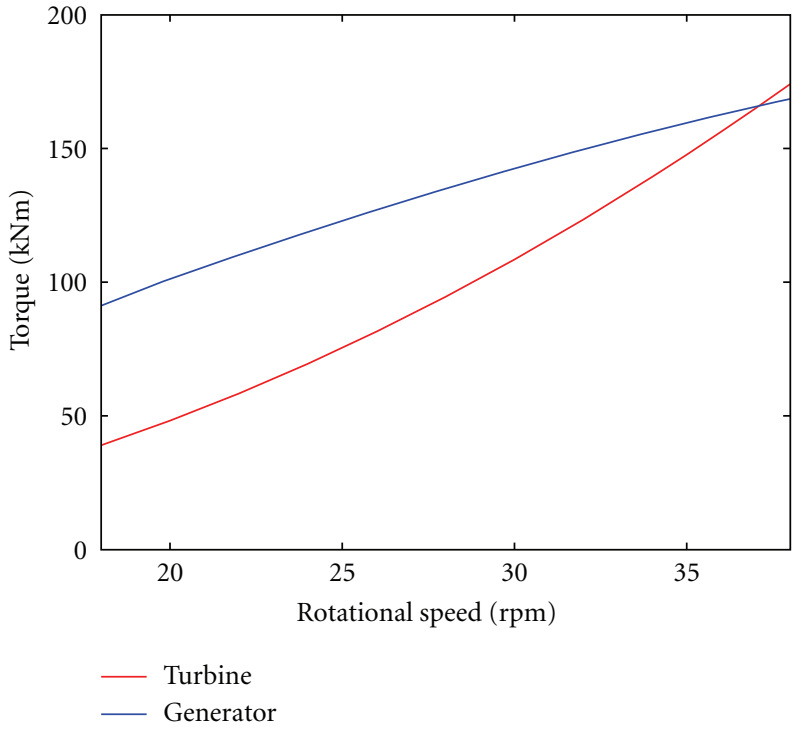

FIGURE 3: Generator braking torque with a dump load of $1.1 \Omega$ per phase and the turbine torque at an extreme gust.

a rotational speed well above $33 \mathrm{rpm}$ will not be reached since the dump load is triggered immediately if the rotational speed exceeds $33 \mathrm{rpm}$.

The torque changes with different rotational speeds, which is an inherent characteristic of a fixed resistive load. The braking procedure will automatically be smooth, since the braking torque decreases with decreasing rotational speed. If the rotational speed would increase uncontrollably both the turbine torque and the braking torque would increase. However, as long as the rotational speed does not increase above $37.1 \mathrm{rpm}$, the dump load will be able to brake the turbine even for an extreme gust.

The intrinsic passive stall control of the turbine works as a self-protection for the generator and the shaft as well as for the electrical system. The generator and the shaft are protected against too high currents and torques as long as the generator is able to control the turbine speed. If the rotational speed is kept constant and the wind speed increases rapidly, 


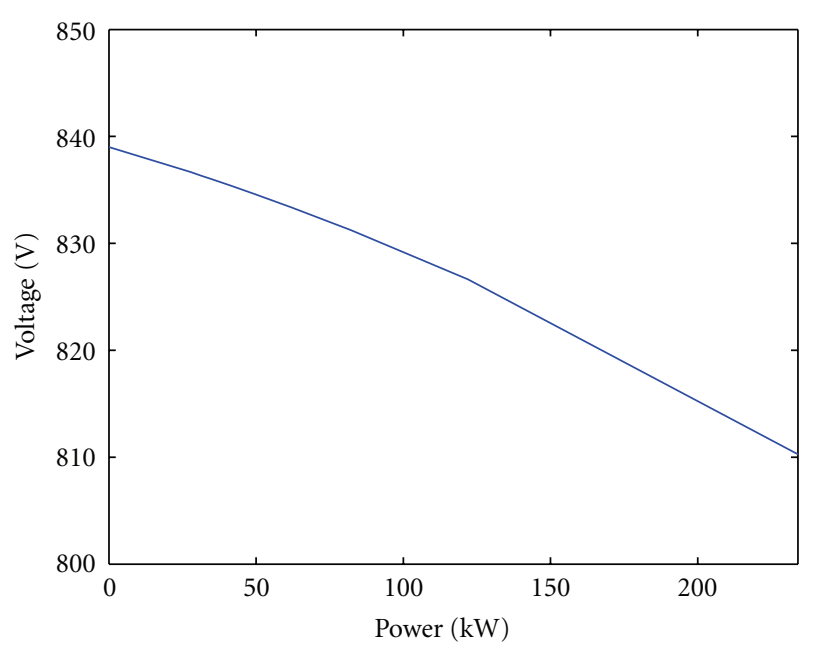

FIGURE 4: Visualisation of the small armature reaction for a constant rotational speed of $33 \mathrm{rpm}$ shown as voltage drop in the L-L voltage at increasing power.

the turbine will start to stall and absorb less power; that is, no high currents will be reached. If the turbine speed, is not longer controlled and exceeds the rated speed the dump load will be triggered. However, high currents and torques can still be reached during faults such as short circuits.

4.2.3. Armature Reaction. Results from simulations of the voltage drop at a fixed rpm and varying load is shown in Figure 4. The armature reaction is low, which is a result of the low reactance. The low voltage drop is an important feature for a generator connected to diodes. If the voltage drop would have been large, the current would have been increased at high loading, resulting in increased resistive losses.

4.3. Experimental Verification of Simulations. The magnetic flux density has been measured along a tangential line in the middle of the generator airgap for two adjacent magnets; see Figure 5. The flat shape of the magnetic flux density is due to the wide and flat magnets. The jagged shape of the magnetic flux density is caused by the stator teeth; see Figure 1 . In both Figures 1 and 5 it can be seen that about five teeth are opposite to each magnet. The experiments correspond very well with simulations. However, in the experiments the magnetic flux density is smaller for the magnet with the positive flux than for the magnet with the negative flux. This is probably due to the rather large tolerances of remanence for the magnets.

The no-load phase voltage has been measured at $18.5 \mathrm{rpm}$; see Figure 5. Results from experiments coincide with simulations. However, the amplitude of the measured voltage is slightly lower for the negative voltage than for the positive voltage. This is due to the generator slowly decelerating while the measurements were made. The rms value of the no-load phase voltage at $18.5 \mathrm{rpm}$ was $271.3 \mathrm{~V}$ according to the simulations and $269.8 \mathrm{~V}$ in the experiments. The experimental result corresponds to a line-to-line voltage at rated speed of $838 \mathrm{~V}$, which was expected from simulations to be $839 \mathrm{~V}$.

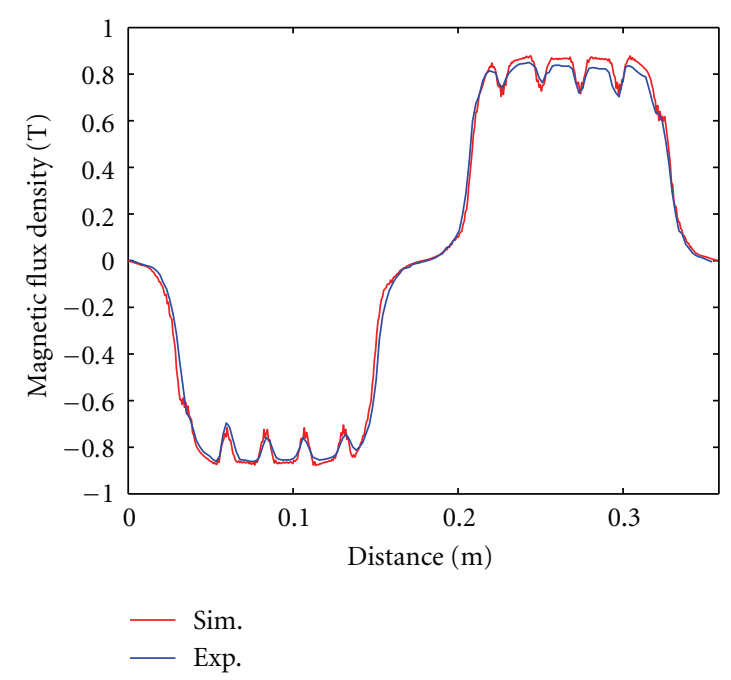

(a)

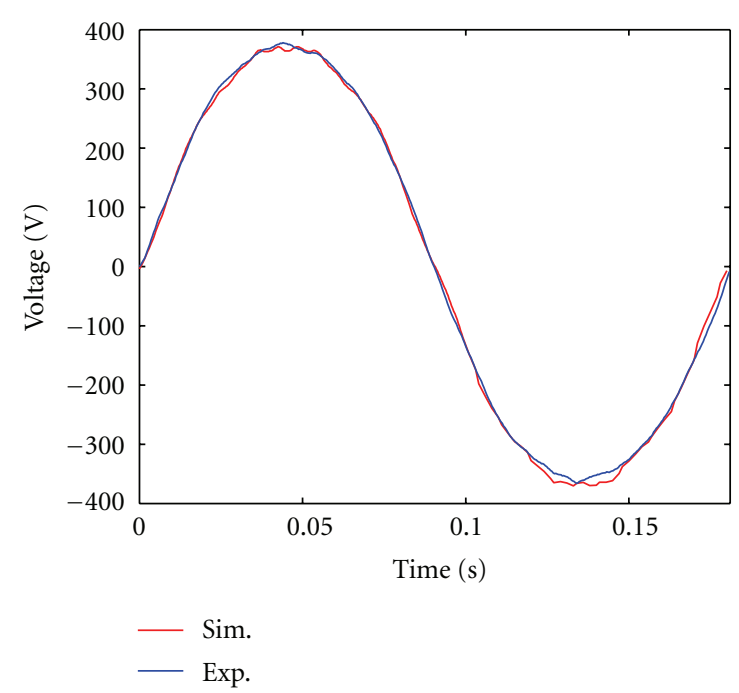

(b)

Figure 5: (a) The magnetic flux density in the generator airgap. (b) Phase voltage at $18.5 \mathrm{rpm}$. Experimental results are compared to simulations.

\section{Conclusions}

A unique direct driven permanent magnet synchronous generator is presented, and the design objectives are motivated. Some important design features are analysed. It is concluded that the efficiency remains high during the whole operational range. Furthermore, the braking torque, calculated for a resistive load of $1.1 \Omega$, shows that the generator can brake the turbine during the whole operational regime even in extreme loads, which makes operation safe and reliable. Thereby, electrically induced stall control has been demonstrated, made possible by the low load angle of the machine and the resulting overload capacity. Furthermore, simulations confirm that the voltage drop in the generator is low due to its low reactance. 
Results from experiments verify the simulations. The generator is now installed in a $200 \mathrm{~kW}$ vertical axis wind turbine built in Falkenberg, Sweden.

\section{Acknowledgments}

Dr. Arne Wolfbrandt and Dr. Urban Lundin are acknowledged for assistance with electromagnetic FEM simulations. David Österberg is acknowledged for providing data for the aerodynamic efficiency and turbine torque. Acknowledgments are given to Vertical Wind, E.ON, Falkenberg Energy, and the Swedish Energy Agency. The Swedish Energy Agency, Vinnova, and Statkraft are acknowledged for contributions to Swedish Centre for Renewable Electric Energy Conversion. This research was carried out as part of the Statkraft Ocean Energy Research Program, sponsored by Statkraft (http://www.statkraft.no/). This support is gratefully acknowledged.

\section{References}

[1] A. D. Hansen, "Generators and power electronics for wind turbines," in Wind Power in Power Systems, T. Ackermann, Ed., pp. 55-65, John Wiley \& Sons, New York, NY, USA, 2005.

[2] S. Eriksson, Direct Driven Generators for Vertical Axis Wind Turbines, Digital Comprehensive Summaries of Uppsala Dissertations from the Faculty of Science and Technology, 2008.

[3] P. Lampola, Directly driven, low-speed permanent-magnet generators for wind power applications, Ph.D. thesis, Department of Electrical Engineering, Helsinki University of Technology, 2000.

[4] A. Grauers, Design of direct driven permanent magnet generators for wind turbines, Ph.D. thesis, Department of Electric Power Engineering, Chalmers University of Technology, 1996.

[5] S. Eriksson, H. Bernhoff, and M. Leijon, "Evaluation of different turbine concepts for wind power," Renewable and Sustainable Energy Reviews, vol. 12, no. 5, pp. 1419-1434, 2008.

[6] G. J. M. Darrieus, "Turbine having its rotating shaft transverse to the flow of the current," US Patent No. 1.835.018, 1931.

[7] J. Kjellin, F. Bülow, S. Eriksson, P. Deglaire, M. Leijon, and H. Bernhoff, "Power coefficient measurement on a $12 \mathrm{~kW}$ straight bladed vertical axis wind turbine," Renewable Energy, vol. 36, no. 11, pp. 3050-3053, 2011.

[8] S. Eriksson, A. Solum, H. Bernhoff, and M. Leijon, "Simulations and experiments on a $12 \mathrm{~kW}$ direct driven PM synchronous generator for wind power," Renewable Energy, vol. 33, no. 4, pp. 674-681, 2008.

[9] S. Eriksson, H. Bernhoff, and M. Leijon, "FEM simulations and experiments of different loading conditions for a $12 \mathrm{~kW}$ direct driven PM synchronous generator for wind power," International Journal of Emerging Electric Power Systems, vol. 10, no. 1, article 3, 2009.

[10] Anon. 1, "Ace, Modified Version 3.1, ABB common platform for field analysis and simulations," ABB Corporate Research Centre, $\mathrm{ABB} \mathrm{AB}$, Corporate Research, 72178 Västerås, Sweden.

[11] A. Broddefalk and M. Lindenmo, "Dependence of the power losses of a non-oriented 3\% Si-steel on frequency and gauge," Journal of Magnetism and Magnetic Materials, vol. 304, no. 2, pp. e586-e588, 2006.
[12] C. C. Mi, G. R. Slemon, and R. Bonert, "Minimization of iron losses of permanent magnet synchronous machines," IEEE Transactions on Energy Conversion, vol. 20, no. 1, pp. 121-127, 2005.

[13] L. Ma, M. Sanada, S. Morimoto, and Y. Takeda, "Prediction of iron loss in rotating machines with rotational loss included," IEEE Transactions on Magnetics, vol. 39, no. 4, pp. 2036-2041, 2003.

[14] Anon. 2, "Electric Steel Non Oriented Fully Processed Cogent," Cogent 2002-11 by SIR-Gruppen Sweden, Surahammars Bruk AB, Box 201, SE-735 23 Surahammar, Sweden.

[15] F. Bülow, S. Eriksson, and H. Bernhoff, "No-load core loss prediction of PM generator at low electrical frequency," Renewable Energy. In press.

[16] S. Eriksson and H. Bernhoff, "Loss evaluation and design optimisation for direct driven permanent magnet synchronous generators for wind power," Applied Energy, vol. 88, no. 1, pp. 265-271, 2011.

[17] I. Paraschivoiu, Wind Turbine Design with Emphasis on Darrieus Concept, Polytechnic International Press, Quebec, Canada, 1st edition, 2002.

[18] International standard IEC 61400-1, 3rd edition, 2005-08. Wind turbines_-part 1: design requirements, International Electrotechnical Commission, Switzerland.

[19] M. Leijon, M. Dahlgren, L. Walfridsson, L. Ming, and A. Jaksts, "A recent development in the electrical insulation systems of generators and transformers," IEEE Electrical Insulation Magazine, vol. 17, no. 3, pp. 10-15, 2001.

[20] P. Kundur, Power System Stability and Control, The EPRI Power System Engineering Series, McGraw-Hill, New York, NY, USA, 1994.

[21] T. A. Loehlein, "Calculating generator reactances," white paper, power topic \#6008, Technical information from Cummins Power Generation, 2006. 

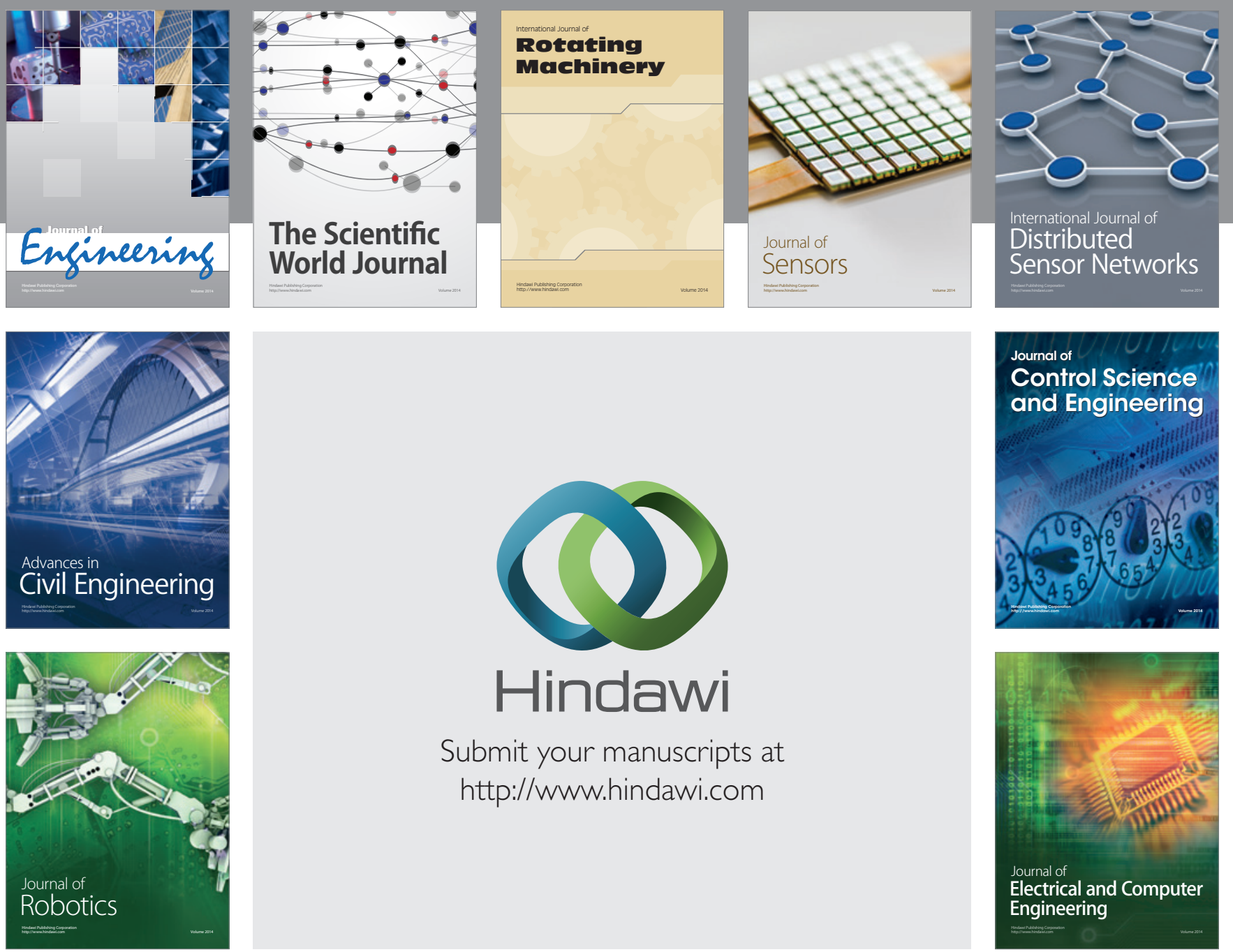

Submit your manuscripts at

http://www.hindawi.com
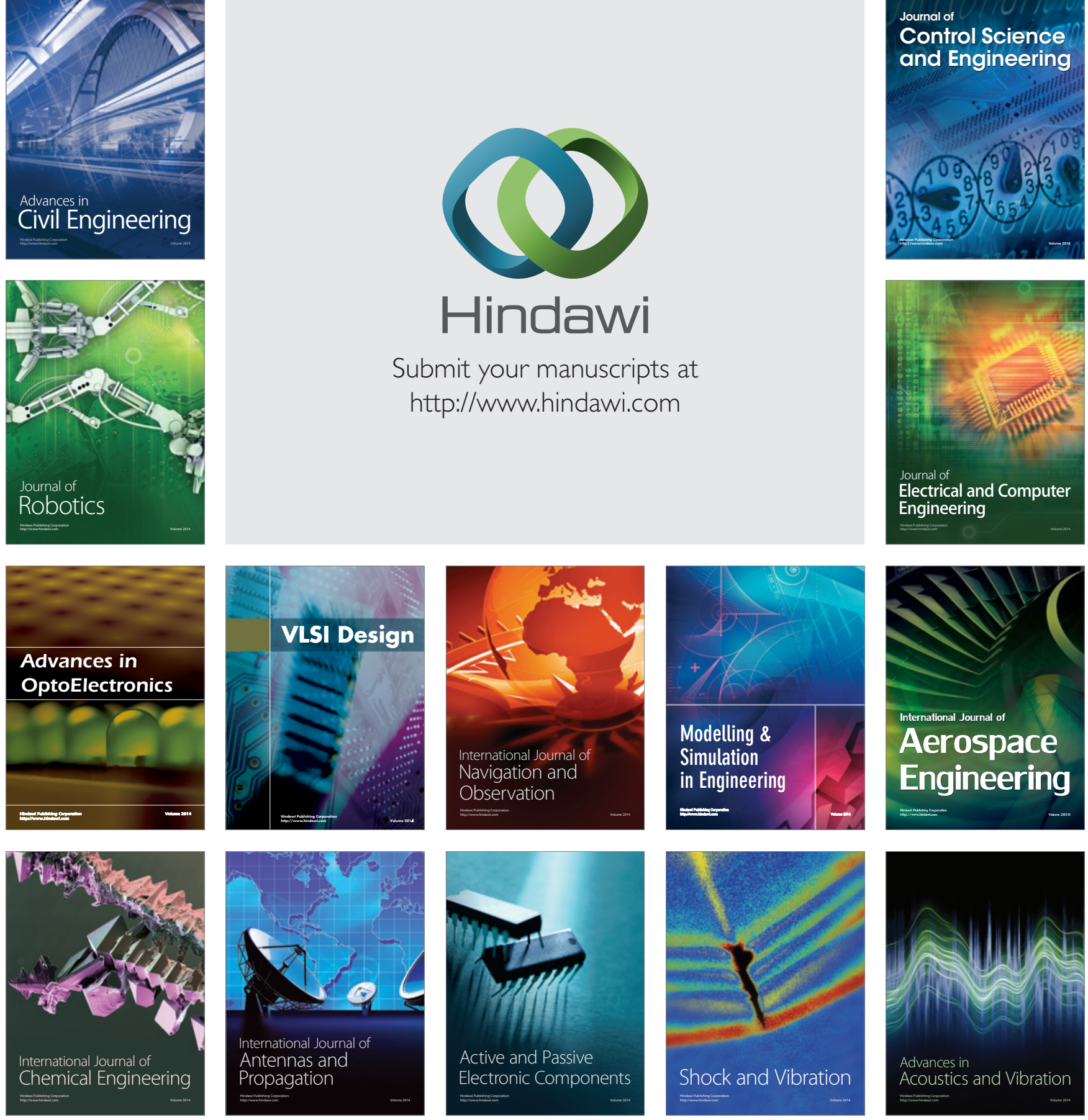